\title{
Avaliação da microbiota presente nas escovas dentais de pacientes infantis durante a internação hospitalar: Estudo piloto
}

Evaluation of the microbiota present in toothbrushes of infant patients during hospitalization: Pilot study

Evaluación de la microbiota presente en cepillos de dientes de pacientes pediátricos durante la hospitalización: Estudio piloto

Diego de Andrade Teixeira ORCID: https://orcid.org/0000-0001-8636-6043 Universidade do Grande Rio, Brasil E-mail: diegodeandradeodontologia@gmail.com

Larissa Parada Leite ORCID: https://orcid.org/0000-0002-4195-8931 Universidade do Estado do Rio de Janeiro, Brasil E-mail: lari.paradal@gmail.com

Silvio Jorge Machado ORCID: https://orcid.org/0000-0002-5960-6520 Universidade do Grande Rio, Brasil E-mail: sjorge@unigranrio.com.br Leila Chevitarese

ORCID: https://orcid.org/0000-0002-5037-8787 Universidade do Grande Rio, Brasil E-mail: 1chevitarese@unigranrio.edu.br Luciana Alves Herdy da Silva ORCID: https://orcid.org/0000-0001-5153-377X Universidade do Grande Rio, Brasil E-mail: 1herdy@unigranrio.com.br

Flávia Cariús Tesch Ferreira Alves ORCID: https://orcid.org/0000-0001-9074-2603 Universidade do Grande Rio, Brasil E-mail: flavia.alves@unigranrio.edu.br José Massao Miasato ORCID: https://orcid.org/0000-0002-0357-542X Universidade do Grande Rio, Brasil E-mail: jmassao@unigranrio.edu.br

\begin{abstract}
Resumo
Este estudo teve como objetivo avaliar a possível contaminação bacteriana nosocomial de escovas dentais de pacientes pediátricos e correlacionar esses achados com as condições de armazenamento. $\mathrm{O}$ estudo foi desenvolvido com pacientes internados em um hospital público do Rio de Janeiro. Apenas pacientes internados por pelo menos três dias na enfermaria pediátrica foram incluídos. Pacientes oncológicos, imunossuprimidos e com infecções respiratórias graves foram excluídos. Dez escovas de dente pessoais foram coletadas e imediatamente transferidas para o Laboratório de Microbiologia. A identificação bacteriana foi realizada por meio de cultura seletiva, coloração de Gram e testes bioquímicos (hidrólise de uréia, indol, catalase e coagulase conjugada). Além disso, testes de sensibilidade antimicrobiana foram realizados para detectar Staphylococcus aureus resistente à meticilina e resistente à vancomicina. A idade do paciente e o tempo de internação foram de 10,5 anos e em média 8,8 dias. Trinta e três por cento das escovas dentais foram armazenadas expostas ao ambiente hospitalar, sem qualquer proteção. Acinetobacter spp. foram identificados em 33\% e Pseudomonas aeruginosa em 22\% das amostras. Além disso, um total de $11 \%$ das amostras estavam contaminadas por Staphylococcus aureus resistente à meticilina e resistente à vancomicina. A contaminação bacteriana hospitalar de escovas dentais, inclusive por Staphylococcus aureus resistente a antibióticos, foi frequente e fortemente associada à sua exposição direta ao ambiente hospitalar. Esses resultados enfatizam a importância da implementação de estratégias para prevenir a contaminação bacteriana das escovas de dente de pacientes hospitalizados.
\end{abstract}

Palavras-chave: Escovação dentária; Contaminação; Infecção hospitalar. 


\begin{abstract}
This study aimed to evaluate the possible nosocomial bacterial contamination of toothbrushes from pediatric patients and correlate these findings with the storage conditions. The study was developed with patients admitted to a public hospital in Rio de Janeiro. Only patients hospitalized for at least three days in the pediatric ward were included. Oncologic, immunosuppressed, and patients with severe respiratory infections were excluded. Ten personal toothbrushes were collected and immediately transferred to the Microbiology Laboratory. Bacterial identification was carried out by selective culture media, Gram stain, and biochemical tests (urea hydrolysis, indole, catalase, and conjugated coagulase). Furthermore, antimicrobial sensitivity tests were performed to detect methicillin-resistant and vancomycin-resistant Staphylococcus aureus. Patient's age and hospitalization period were 10.5 years and 8.8 days in mean. Thirty-three toothbrushes were stored exposed to the hospital environment, without any protection. Acinetobacter spp. were identified in $33 \%$ and Pseudomonas aeruginosa in $22 \%$ of the samples. Additionally, a total of $11 \%$ of samples were contaminated by methicillin-resistant and vancomycin-resistant Staphylococcus aureus. Nosocomial bacterial contamination of toothbrushes, including by antibiotic-resistant Staphylococcus aureus, was frequent and strongly associated with their direct exposure to the hospital environment. These results emphasize the importance of implementing strategies to prevent the bacteria contamination of hospitalized patient's toothbrushes.
\end{abstract}

Keywords: Toothbrushing; Contamination; Hospital infection.

\title{
Resumen
}

Este estudio tuvo como objetivo evaluar la posible contaminación bacteriana nosocomial de los cepillos de dientes de pacientes pediátricos y correlacionar estos hallazgos con las condiciones de almacenamiento. El estudio se desarrolló con pacientes ingresados en un hospital público de Río de Janeiro. Solo se incluyeron pacientes hospitalizados durante al menos tres días en la sala de pediatría. Se excluyeron pacientes oncológicos, inmunosuprimidos y con infecciones respiratorias graves. Se recogieron diez cepillos de dientes personales y se trasladaron inmediatamente al Laboratorio de Microbiología. La identificación bacteriana se realizó mediante medios de cultivo selectivos, tinción de Gram y pruebas bioquímicas (hidrólisis de urea, indol, catalasa y coagulasa conjugada). Además, se realizaron pruebas de sensibilidad a los antimicrobianos para detectar Staphylococcus aureus resistente a la meticilina y a la vancomicina. La edad del paciente y el período de internación fueron de 10,5 años y 8,8 días de media. El treinta y tres por ciento de los cepillos de dientes se almacenaron expuestos al ambiente hospitalario, sin ninguna protección. Acinetobacter spp. se identificaron en el 33\% y Pseudomonas aeruginosa en el 22\% de las muestras. Además, un total del $11 \%$ de las muestras estaban contaminadas por Staphylococcus aureus resistente a la meticilina y a la vancomicina. La contaminación bacteriana nosocomial de los cepillos de dientes, incluso por Staphylococcus aureus resistente a los antibióticos, fue frecuente y estuvo fuertemente asociada con su exposición directa al ambiente hospitalario. Estos resultados enfatizan la importancia de implementar estrategias para prevenir la contaminación bacteriana de los cepillos de dientes de los pacientes hospitalizados.

Palabras clave: Cepillado de dientes; Contaminación; Infección hospitalaria.

\section{Introdução}

Há bastante tempo a higiene oral é uma prática comum. Na Babilônia, em 3500 a.C, a limpeza dos dentes era realizada através de palitos de ouro. Já Aristóteles, em 350 a.C, utilizava uma toalha de linho fino para realizar sua higiene. Porém, as escovas modernas, parecidas com as de hoje, surgiram por volta da década de 1930 (Barros et al, 2011). No Brasil, até o final do século XX, a saúde bucal esteve longe das políticas de saúde pública, e grande parte da população, principalmente as classes C e D, não obtinham acesso a serviços odontológicos. Somente a partir de 2003, com a criação da Política Nacional de Saúde Bucal, pelo Ministério da Saúde, houve melhora na oferta e nos cuidados a população (Teixeira et al, 2017).

A escova dental é o instrumento mais eficiente e seguro para higienização oral (Oliveira et al, 2009). Sua função é desorganizar e remover mecanicamente o biofilme, aderido ao dente e sobre as superfícies bucais, de modo que reduz a diversidade microbiana e mantém o equilíbrio da flora oral. Porém, cuidados no seu armazenamento e uso devem ser adotados por serem instrumentos de fácil contaminação, por diversos microrganismos (bactérias, vírus e fungos), desde seu processo de fabricação. Diversos fatores influenciam em sua contaminação, como o tipo de ancoragem das cerdas, número de tufos, o acondicionamento inadequado, o ambiente a que a escova é exposta, inclusive a própria cavidade oral, diretamente ou indiretamente (Gonçalo \& Mialhe, 2009). Os índices de infecção estão intimamente relacionados à forma de armazenamento e ao ambiente em que estão submetidas (Moreira \& Cavalcante, 2008). 
O ambiente hospitalar é controlado por uma Comissão de Controle de Infecção Hospitalar (CCIH), que tem por objetivo diminuir os riscos para os pacientes, visitantes e trabalhadores. De acordo com a Portaria MS n 2616 de 12/05/1998, é considerada Infecção Hospitalar (IH) qualquer infecção adquirida posteriormente à admissão do paciente, com manifestação clínica durante o período de internação ou após a alta hospitalar, e apresentar relação com a internação ou a procedimentos realizados durante o período desta. A IH é uma preocupação mundial e apresenta como consequências principais a elevação dos custos com o paciente, o aumento do tempo de internação e das taxas de mortalidade, sendo considerado um caso de saúde pública (Anelo \& Caregnato, 2018; Farias et al, 2020).

Microrganismos como Staphylococcus aureus e Acinetobacter spp. podem levar o paciente a um estágio crítico de saúde. Staphylococcus aureus é o principal responsável por infecções em Unidades de Terapia Intensiva (UTI) Pediátricas, podendo levar a quadros de sepse, complicações neurológicas, como a embolia cerebral e falência múltipla dos órgãos (Song et al, 2018). Já Acinetobacter está associado principalmente à meningite nosocomial e capaz de provocar sequelas neurológicas permanentes atingindo uma alta taxa de mortalidade (Pormohammad et al, 2020).

Tendo conhecimento que as escovas dentais podem ser colonizadas por diversos tipos de microrganismos, assim como podem ser responsáveis pela disseminação destes, compreende-se a relevância de ponderar sobre esse instrumento, fundamental para a higiene oral, nos diversos ambientes que possam contaminá-lo. Contudo, existem poucos estudos na literatura que abordam a contaminação de patógenos ligados diretamente a IH. O presente estudo teve por objetivo avaliar a forma de armazenamento e a possível contaminação por bactérias relacionadas à IH nas escovas de pacientes pediátricos internados em um hospital público do Rio de Janeiro.

\section{Metodologia}

O estudo foi submetido e aprovado pelo Comitê de Ética em Pesquisa (CEP) da UNIGRANRIO, protocolo ${ }^{\circ}$ 20085819.7.0000.5283. A pesquisa foi realizada através de uma amostra de conveniência, composta por 10 voluntários internados em uma enfermaria pediátrica de um hospital público do Estado do Rio de Janeiro e o período da coleta estipulado foi de 1 semana devido às limitações impostas pela pandemia de SARS-CoV-2.

Após a obtenção das assinaturas do Termo de Consentimento Livre e Esclarecido (TCLE), os responsáveis legais responderam a um questionário contendo questões como: idade, tempo de internação, frequência de escovação e a forma de armazenamento da escova dental. Em seguida a escova era coletada e embalada em papel grau cirúrgico, previamente esterilizado em autoclave. Apenas um pesquisador realizou as coletas. A cada voluntário foi entregue uma nova escova dental.

Foram considerados critérios de inclusão: pacientes internados por no mínimo três dias na enfermaria pediátrica, que assinaram o TCLE. Foram considerados critérios de exclusão: pacientes oncológicos, pacientes internados por infecções respiratórias graves e pacientes imunossuprimidos.

Ao fim de cada coleta, a escova foi imediatamente levada ao Laboratório Multidisciplinar da UNIGRANRIO, e foi inoculada em tubo de ensaio, contendo $20 \mathrm{ml}$ de caldo Brain Heart Infusion (BHI) (Merck KGaA, Darmstadt, Alemanha), com a cabeça voltada para baixo, de modo que o meio de cultura cobrisse totalmente as cerdas. Os tubos foram devidamente vedados com algodão hidrofóbico e incubados em estufa a $37^{\circ} \mathrm{C}$, durante 24 horas, em aerobiose. Após esse período de incubação, as culturas crescidas no caldo BHI foram repicadas e semeadas, por esgotamento, no meio de cultura Ágar Sangue (Plast Labor, Rio de Janeiro, Brasil). Após esse período de incubação, as amostras foram repicadas em meios de culturas diferenciais e seletivos: Ágar Sal Manitol (Merck KGaA, Darmstadt, Alemanha), Ágar EMB (Merck KGaA, Darmstadt, Alemanha), Ágar Bismuto-Sulfito (Merck KGaA, Darmstadt, Alemanha), Ágar Mueller Hinton (Merck KGaA, Darmstadt, Alemanha), Ágar Sabouraud (suplementado com uma solução de Ácido Tartárico a 10\%, com o objetivo de reduzir o pH em relação ao pH normal da solução) (Merck KGaA, Darmstadt, Alemanha) e Ágar MacConkey (Merck KGaA, Darmstadt, 
Alemanha).

O processo de identificação bacteriana ocorreu pela análise macroscópica das placas para identificação nos meios de cultura diferenciais e seletivos; foi realizada também a técnica de coloração de Gram de todas as diferentes colônias de bactérias para a identificação morfotintorial das bactérias Gram positivas e Gram negativas e, posteriormente, a análise microscópica. Foram realizadas provas bioquímicas de identificação bacteriana: Hidrólise da Ureia (para a diferenciação entre os gêneros Proteus e Salmonella), Indol (para a caracterização de micro-organismos pertencentes à família Enterobacteriaceae), Catalase e Coagulase Conjugada (para confirmação de Staphylococcus aureus). Além disso, foram realizados Testes de Sensibilidades a Antimicrobianos (TSA) (Sensifar-Cefar, Rio de Janeiro, Brasil) com discos de Oxacilina

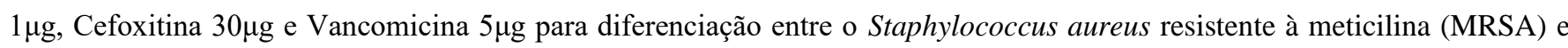
Staphylococcus aureus resistente à vancomicina (VRSA).

Ao fim de todo o processo, realizou-se a análise descritiva dos dados.

\section{Resultados}

Foi coletado um total de 10 escovas, sendo a amostra de número 09 excluída, por erro no condicionamento da escova entre a coleta e o envio para o laboratório. A amostra de número 04 foi excluída do cálculo de tempo de internação média, visto que, a internação do paciente não correspondia ao padrão de internação da enfermaria, que é de no máximo 40 dias.

O tempo médio de internação dos voluntários, em dias, foi de 8,8 dias; a média de idade dos voluntários foi de 10,5 anos; 7 voluntários eram do sexo feminino e 3 do sexo masculino; 5 voluntários relataram escovar os dentes 3 vezes ao dia, 3 voluntários relataram escovar os dentes 2 vezes ao dia, 2 voluntários relataram escovar os dentes 1 vez ao dia e $33 \%$ das escovas eram armazenadas expostas ao meio hospitalar. Não foi encontrada nenhuma espécie de fungos. Nenhum voluntário relatou não escovar os dentes ou escovar mais de 3 vezes ao dia.

Na Tabela 1, é possível observar a prevalência dos micro-organismos encontrados nas escovas, o tempo médio de internação, a forma de armazenamento da escova e a frequência média de escovação diária. 
Tabela 1. Prevalência dos micro-organismos identificados.

\begin{tabular}{|c|c|c|c|c|c|}
\hline & & & Tempo & Armazenada & Frequência \\
\hline Variável & $\mathbf{N}$ & $\%$ & $\begin{array}{l}\text { Médio de } \\
\text { dias de } \\
\text { internação } \\
\text { (dias) }\end{array}$ & $\begin{array}{l}\text { exposta ao } \\
\text { meio } \\
\text { hospitalar }\end{array}$ & $\begin{array}{l}\text { média de } \\
\text { escovação } \\
\text { diária }\end{array}$ \\
\hline
\end{tabular}

\begin{tabular}{|c|c|c|c|c|c|}
\hline Microorganismo & & & & & \\
\hline Acinetobacter & 3 & $33 \%$ & 6 & $66 \%$ & 2 \\
\hline Pseudomonas aeruginosa & 2 & $22 \%$ & 5 & $50 \%$ & 1,5 \\
\hline $\begin{array}{l}\text { Staphylococcus aureus } \\
\text { MRSA }\end{array}$ & 1 & $11 \%$ & $1462 *$ & $100 \%$ & 1 \\
\hline $\begin{array}{l}\text { Staphylococcus aureus } \\
\text { VRSA }\end{array}$ & 1 & $11 \%$ & 5 & $100 \%$ & 2 \\
\hline Staphylococcus aureus & 3 & $33 \%$ & 12 & $66 \%$ & 3 \\
\hline Escherichia coli & 2 & $22 \%$ & 3 & $50 \%$ & 3 \\
\hline Klebisiella spp & 6 & $66 \%$ & 11,8 & $66 \%$ & 2,3 \\
\hline Enterobacter spp & 3 & $33 \%$ & 7 & $33 \%$ & 1,6 \\
\hline Salmonella spp & 8 & $88 \%$ & 9,5 & $50 \%$ & 2,3 \\
\hline S. Epidermidis & 2 & $22 \%$ & 17,5 & $50 \%$ & 3 \\
\hline $\begin{array}{l}\text { Corynebacterium } \\
\text { diphtheriae }\end{array}$ & 1 & $11 \%$ & 9 & - & 3 \\
\hline Proteus mirabilis & 1 & $11 \%$ & 9 & - & 3 \\
\hline
\end{tabular}

Legenda: * A amostra em que o MRSA foi encontrado não entrou no cálculo de tempo médio de internação. - Nenhuma amostra foi armazenada exposta ao meio hospitalar. Fonte: Autores.

Foi identificado, nas escovas dentais, micro-organismos relacionados à IH como: Acinetobacter spp. em três amostras, Pseudomonas spp. em duas amostras, Staphylococcus aureus MRSA em uma amostra e Staphylococcus aureus VRSA em uma amostra, sendo estes encontrados em amostras que estavam armazenadas diretamente expostas ao meio hospitalar. O microorganismo mais frequentemente identificado foi Salmonella spp. Outros micro-organismos identificados podem ser considerados achados microbiológicos, visto que, não estão relacionados diretamente com a IH.

\section{Discussão}

De acordo com os dados expostos, pôde-se observar a presença de um elevado número de amostras contaminadas por Salmonella spp., o que pode sugerir uma contaminação da água que os pacientes utilizam para realizar a higiene oral ou em algum momento da execução da higiene oral no banheiro, visto que alguns indivíduos podem se tornar portadores assintomáticos, por meses ou anos, em que apesar da ausência de sintomatologia estão infectados, constituindo assim uma fonte contínua de transmissão (Marcondes et al, 2016). Não houve nenhum relato de pacientes com a presença sinais e/ou sintomas sugestivos de Salmonelose (doença causada pela infecção por Salmonella spp.), como distúrbios gastrintestinais e febre, na unidade durante o período avaliado, considerando os pacientes que tiveram ou não suas escovas dentais avaliadas. Além disso, outro ponto que sugere a contaminação no momento da higiene oral é a utilização de um único local por todos os pacientes internados na enfermaria.

Foram utilizados dois tipos de discos antibióticos para testar a sensibilidade de Staphylococcus aureus à meticilina (oxacilina $1 \mu \mathrm{g}$ e cefoxitina $30 \mu \mathrm{g}$ ), dado que a meticilina não é mais produzida. A cefoxitina é considerada o antibiótico de 
primeira escolha, pois nos discos com oxacilina algumas cepas de hiperprodutores de penicilinase não resultam em zona de inibição, e serão identificados como MRSA equivocadamente (Zurita et al, 2010).

A contaminação por Staphylococcus aureus MRSA e Staphylococcus aureus VRSA estava presente em amostras que foram armazenadas totalmente expostas ao meio ambiente hospitalar, o que indica a necessidade de adoção de protocolos de armazenamentos, assim como instruções de acondicionamento das escovas dentais. A American Dental Association recomenda que as escovas devam ser guardadas em uma posição vertical, limpas, sem resíduos de creme dental ou alimentos, em local que permita a secagem rápida e, quando guardada juntos a outras escovas, devam ser separadas para que impeça o contato direto entre estas (Teitelbaum et al, 2008; Gonçalo \& Mialhe, 2009). Ferreira (2013) sugere que o melhor local para acondicionar é o armário do banheiro.

A contaminação das escovas por Escherichia coli, Corynebacterium diphtheriae e Proteus mirabilis provavelmente adveio de local fora da unidade de internação, sendo esses micro-organismos encontrados em diversos estudos com frequência fora do ambiente hospitalar (Teitelbaum et al, 2008; Araújo et al, 2014). Para mais, pode-se considerar também, o baixo número de escovas contaminadas e o baixo número de dias de internação dos pacientes.

A cárie e a doença periodontal são as principais doenças que acometem o sistema estomatognático, e a escovação dental é o método mais efetivo para a desorganização e a remoção mecânica do biofilme, fator determinante para o avanço da cárie e da doença periodontal, reduzindo-as efetivamente (Ferreira et al, 2013).

O acúmulo, difusão e a descontaminação dos microrganismos na escova dental são influenciados diretamente pelo tipo de inserção das cerdas; a superfície em que estas são fixadas na cabeça da escova é a região mais propicia para o crescimento microbiano, em razão da existência de espaços vazios, que podem acumular restos alimentares e de dentifrício. Diversas técnicas de afixação dos tufos visam eliminar esses espaços vazios e promover uma limpeza mais eficaz. Também é observado que escovas dentais coloridas são mais suscetíveis a contaminação, dado que sua coloração camufla os resíduos alimentares e de dentifrício fluoretado, de modo que torna ineficaz a limpeza destes instrumentos (Gonçalo \& Mialhe, 2009).

Existem diversas técnicas de sanificação e descontaminação das escovas dentais. Aquelas que utilizam agentes químicos são mais eficientes e possuem um custo menor. O hipoclorito de sódio a $1 \%$ foi o agente que demostrou maior eficiência, porém seu uso contínuo não é recomendado, pois pode acarretar distúrbios estomacais e irritações das mucosas periodontais. Com isso, o álcool 77\% e o Gluconato de Clorexidina a $0,12 \%$ são alternativas viáveis ao hipoclorito (Gonçalo \& Mialhe, 2009; Camargo et al, 2013; Busato et al, 2015). Ademais, Nesso \& Iembo (2012) em seu estudo demonstra que o forno micro-ondas pode ser utilizado para desinfetar as escovas dentais, no entanto, deve-se observar a potência de cada forno e o tempo que deve ser utilizado, visto que as escovas se deformaram após a esterilização, o que sugere o desenvolvimento de outros estudos que proponham um tempo padrão com determinada potencia para que ocorra a descontaminação sem a deformação do plástico da escova dental.

Em março de 2020, a Organização Mundial da Saúde (OMS) declarou pandemia pela COVID-19. Este novo coronavírus (SARS-CoV-2) pode ser transmitido através do contato direto, ou indireto, com as mucosas dos olhos, nariz ou boca, sendo esta última um grande reservatório do vírus, principalmente na língua. Com isso, é possível haver contaminação cruzada pela escova dental e pelo tubo de dentifrício fluoretado e, a partir disso, diversos enxaguatórios orais, disponíveis no mercado, estão sendo avaliados quanto à eficácia em reduzir a carga viral oral. Entretanto, ainda não há dados disponíveis sobre o uso de substâncias para a desinfecção de escovas dentais contra SARS-CoV-2, e os enxaguatórios bucais a base de clorexidina não demonstraram eficiência contra esse vírus. Meister (2021) realizou testes in vitro e sugeriu o uso do enxaguatório oral contendo etanol e óleos essenciais (Listerine Cool Mint@) como primeira escolha para desinfectar as escovas dentais, imergindo suas cerdas por 20 min após a escovação. Em ambientes coletivos, como escolas, creches, hospitais e casas de longa permanência para idosos, após a higienização das mãos, é recomendado a limpeza do cabo da escova com álcool 70\% 
por 1 minuto (González-Olmo et al, 2020; Lamarca et al, 2021).

A maior limitação do estudo foi imposta pela pandemia de SARS-CoV-2, que restringiu o acesso ao hospital, com isso impossibilitou a coleta das escovas. Outro ponto de interferência foram as consequências econômicas, pela elevação do custo dos materiais laboratoriais necessários à realização da pesquisa, a canalização de grande parte dos insumos para exames de identificação do novo coronavírus, principalmente pelo método de reação em cadeia de polimerase (PCR), inviabilizando assim, mesmo que momentaneamente, a identificação bacteriana através de seu DNA pelo PCR.

\section{Conclusão}

A partir da análise dos dados, pode-se afirmar que as escovas dentais foram colonizadas por bactérias relacionadas diretamente a infecções hospitalares, inclusive por Staphylococcus aureus resistente a antibióticos, e foi frequente e fortemente associada à sua exposição direta ao ambiente hospitalar. Essas bactérias têm o potencial de desencadear quadros graves de saúde e, consequentemente, eleva os custos do tratamento, o tempo necessário de internação hospitalar, assim como morbidade e mortalidade. Esses resultados enfatizam a importância da implementação de estratégias para prevenir a contaminação bacteriana das escovas de dente de pacientes hospitalizados. Outrossim, propõe-se novos estudos, com uma quantidade maior de amostras para ratificar os resultados.

\section{Referências}

Anelo, T. F. S., \& Caregnato, R. C. A. (2018). Ação educativa direcionada à segurança hospitalar: limpeza e desinfecção do ambiente próximo ao paciente. Vigil. Sanit. Debate, 6(3), 89-95. https://doi.org/10.22239/2317-269x.01101

Araújo, R. J. G., et al. (2014). Contaminação, desinfecção e acondiconamento de escovas dentais. Revista Científica da ABOMI, $29(1), 44-54$.

Barros, O. B., et al. (2001). Escovas dentais. Rev Fac Odontol São José dos Campos, 4(1), 32-37.

Busato, C. A., et al. (2015). Utilização do hipoclorito de sódio na descontaminação de escovas dentais: estudo in vitro. Rev Odontol UNESP, 44(6), 335-339. https://doi.org/10.1590/1807-2577.04214

Camargo, R. A., et al. (2013). Avaliação microbiológica da efetividade de uma escova antibacteriana: um estudo in vivo. Rev Odontol UNESP, 42(1), 54-58.

Faria, L. M. M., et al. (2020). Prevalência de infecções bucais em ambiente hospitalar. Rev Estomato, 28(1), 8-16.

Ferreira, G. T. S., et al. (2013). Verificação da contaminação e forma de armazenamento de escovas dentais em um grupo de adolescentes de uma escola da rede privada de ensino. Rev. odontol. Univ. Cid. São Paulo, 25(1), 6-10.

Gonçalo, C. S., \& Mialhe, F. L. (2009). Contaminação das escovas dentais: Uma revisão crítica da literatura. R. Periodontia, 19(3), 56-63.

González-olmp, M. J., et al. (2020). Oral hygiene habits and possible transmission of COVID-19 among cohabitants. BMC Oral Health, 20(286), 1-7. https://doi.org/10.1186/s12903-020-01274-5

Lamarca, J. H., et al. (2020). SARS-CoV-2: a protocol for disinfection of toothbrushes. The Journal of Infectious Diseases, jiaa794. https://doi.org/10.1093/infdis/jiaa794

Marcondes, M. A., et al. (2016). Isolamento e identificação de Salmonella spp nas águas de rios e córregos do Municipio de São Caetano do Sul - SP. Ciência \& Tecnologia: FAETEC-JB, 8, 1-15.

Meister, T. L. (2020). Virucidal efficacy of different oral rinses against severe acute Respiratory Syndrome Coronavirus 2. The Journal of Infectious Diseases, 222(8), 1289-1292. https://doi.org/10.1093/infdis/jiaa471

Moreira, A. C. S., \& Cavalcante, G. M. (2008). Influência da higienização na contaminação de escovas dentais. Arq. Ciênc. Saúde Unipar, 12(1), 99-103.

Nesso, N., \& Iembo, T. (2012). O uso do forno de micro-ondas como agente antimicrobiano de alguns utensílios domésticos. J Health Sci Ins, 30(4), 315-317.

Oliveira, C. B., et al. (2009). Avaliação da eficácia da descontaminação de escovas dentárias pelo uso do spray de óleo essencial da eugenia uniflora 1. (Pitanga). Cienc Odontol Bras, 12(2), 29-34.

Pormohammad, A., et al. (2020). Global prevalence of colistin resistance in clinical isolates of Acinetobacter baumannii: A systematic review and metaanalysis. Microbial Pathogenesis, 139, 103887. https://doi.org/10.1016/j.micpath.2019.103887

Song, Q., et al. (2018). Predominance of community-associated sequence type 59 methicillin-resistant Staphylococcus aureus in a paediatric intensive care unit. Journal of Medical Microbiology, 67, 408-414. https://doi.org/10.1099/jmm.0.000693 
Research, Society and Development, v. 10, n. 9, e4210917615, 2021

(CC BY 4.0) | ISSN 2525-3409 | DOI: http://dx.doi.org/10.33448/rsd-v10i9.17615

Teitelbaum, A. P., et al. (2008). Contaminação de escovas dentais usadas em crianças com autismo. Rev Inst Ciênc Saúde, 26(1), 111-114.

Teixeira, D. A., et al. (2017). Programa saúde na escola: Uma visão acadêmica. Revista Rede de Cuidados em Saúde, 11(1), 1-9.

Zurita, J., et al. (2010). Diagnóstico e teste de sensibilidade para Staphylococcus aureus resistente à meticilina na América Latina. Braz J Infect Dis, 14(2), 97106. https://doi.org/10.1590/S1413-86702010000800005 